\title{
REFLETINDO CONCEITOS E LEGISLAÇÕES ACERCA DA EDUCAÇÃO INCLUSIVA NA PERSPECTIVA DA PRÁTICA DOCENTE PARA INCLUSÃO
}

\author{
REFLECTING CONCEPTS AND LEGISLATIONS ON INCLUSIVE EDUCATION IN \\ THE PERSPECTIVE OF TEACHING PRACTICE FOR INCLUSION
}

\author{
Édna Leandro da Silva ${ }^{\mathrm{I}}$ \\ Nelson Dias II
}

\section{RESUMO}

A presente pesquisa resultado de um estudo bibliográfico tem o objetivo de realizar reflexões acerca da inclusão, visto que, diversos documentos normativos e planos, a exemplos, da Lei de Diretrizes e Bases da Educação (LDBEN), Estatuto da Criança e do Adolescente (ECA), Política Nacional para a Integração da Pessoa Portadora de Deficiência, Plano Nacional de Educação em Direitos Humanos, dentre outros garantem o direito ao acesso à diversos serviços e espaços educativos e sociais. Uma das responsabilidades das escolas é assegurar um currículo inclusivo, utilizar métodos e recursos que atendam às necessidades de todos os educandos, para cumprir com isso é necessário deixar de lado os métodos tradicionais, visões estereotipadas e arrigadas que favorecem a segregação e exclusão. É no contexto educacional que a criança tem possibilidade de ampliar suas experiências e vivências, que ela amplia os valores, as suas relações sociais e sua constituição como um ser humano, mesmo tendo uma constituição biológica/orgânica diferente das demais. Essas ideias têm como base os pressupostos de Vygotsky que contribuem para problematizar a educação inclusiva. As contribuições de Vygotsky para o desenvolvimento de pessoas com deficiência têm um enfoque qualitativo, que busca compreender o desenvolvimento psicológico em crianças com deficiência, que era fundamental ao projeto intelectual de Vygotsky: propor uma teoria geral do desenvolvimento humano.

Palavras-chave: Educação. Inclusão. Legislações. Práticas Pedagógicas.

\section{ABSTRACT}

The present research, as a result of a bibliographical study, aims at reflecting on inclusion, since several normative documents and plans, such as the Law on Guidelines and Bases of Education (LDBEN), the Statute of Children and Adolescents (ECA), National Policy for the Integration of Persons with Disabilities, National Plan for Human Rights Education, among others guarantee the right to access to various services and educational and social spaces. One of the responsibilities of schools is to ensure an inclusive curriculum, to use methods and resources that meet the needs of all learners, to do this it is necessary to leave aside the traditional methods, stereotyped and arrogant views that favor segregation and exclusion. It is in the educational context that the child has the possibility to broaden their experiences and experiences, that it expands values, their social relations and their constitution as a human being, even having a biological / organic constitution different from the others. These ideas are based on the assumptions of Vygotsky that contribute to problematizing inclusive education. Vygotsky's contributions to the development of people with disabilities have a qualitative approach, which seeks to understand the psychological development in children with disabilities, which was fundamental to Vygotsky's intellectual project: to propose a general theory of human development.

Keywords: Education. Inclusion. Legislation. Pedagogical practices.

\footnotetext{
I Universidade Federal de Mato Grosso do Sul - UFMS, Brasil. E-mail: edna.silva5666@ gmail.com

${ }^{\text {II }}$ Universidade Federal de Mato Grosso do Sul - UFMS, Brasil. E-mail: nelsonufms@ hotmail.com
} 


\section{INTRODUÇÃO}

Tendo em vista os pressupostos teóricos e práticos da inclusão escolar, o presente trabalho situa saberes e práticas inclusivas, considerando a responsabilidade dos envolvidos no processo de ensino-aprendizagem. Partindo do questionamento se as práticas pautadas na ideia da Educação Inclusiva realmente incluem, será problematizada a formação de professores para ações inclusivas no contexto escolar.

Para isso, será levado em consideração as discussões de pesquisadores que dialogam a respeito da temática em estudo, como Vigotski (2011), Carvalho (2011), Barbosa (2015), Nascimento e Gelatti (2015), Lopes e Fabris (2016), dentre outros que possibilitarão refletir sobre a atuação docente. A busca pela compreensão de práticas de educação inclusiva possibilitou colocar em tela a discussão sobre a formação de docente para práticas pedagógicas inclusivas.

Com a intenção de fazer uma reflexão sobre a diversidade encontrada no ambiente escolar e os desafios enfrentados pelos (as) pedagogo (as) na construção de uma escola inclusiva, vislumbramos aproximar o ideal do real com vistas numa efetiva inclusão no contexto escolar. Há de se ponderar, se as ideias sobre a educação inclusiva estão sendo efetivas com a transformação das relações e interações sociais na escola, pautadas no respeitoso da diferença.

Carvalho (2011) destaca que é necessária mudança de atitude frente à deficiência para garantir e assegurar o direito de todas as crianças, pois há um distanciamento longo entre o discurso e a prática. Quanto a esse aspecto, o presente artigo tem como objetivo de refletir acerca da educação inclusiva no sentido das produções na sala de aula, ou seja, no contexto escolar, para isso foram adotados os procedimentos metodológicos apresentados na seção abaixo.

\section{MATERIAL E MÉTODO}

Conforme Gil (2002) a pesquisa exploratória tem como objetivo principal o aprimoramento de ideias, seu planejamento é flexível e na maioria dos casos assume a forma de pesquisa bibliográfica ou de estudo de caso. Assim, a presente pesquisa é caracteriza como exploratória e bibliográfica, pois busca uma maior familiaridade com a temática mediante o levantamento e análise da literatura.

A pesquisa bibliográfica pode ser compreendida como um processo que envolve a escolha do tema, o levantamento bibliográfico preliminar, a formulação do problema, a elaboração do plano provisório de assunto, a busca das fontes, a leitura do material fichamento, organização lógica do assunto e redação do texto (GIL, 2002). Na acepção de Severino (2007) a pesquisa bibliográfica é pautada em estudos que estão disponíveis, e poderá incluir;

[...] registro disponível, decorrente de pesquisas anteriores, em documentos impressos, como livros, artigos, teses etc. Utilizam-se dados de categorias teóricas já trabalhadas por outros pesquisadores e devidamente registrados. Os textos tornam-se fontes dos temas a serem pesquisados. $\mathrm{O}$ pesquisador trabalha a partir de contribuições dos autores dos estudos analíticos constantes dos textos (SEVERINO, 2007, p.122).

Assim, para atender os objetivos da pesquisa 
foi realizada uma busca minuciosa em documentos normativos, bem como em artigos de pesquisas já realizadas. Portanto define-se a presente pesquisa como bibliográfica e documental, segundo Gil (2002, p. 45) pesquisa bibliográfica:

E desenvolvida com base em material já elaborado, constituído principalmente de livros e artigos científicos. Embora em quase todos os estudos seja exigido algum tipo de trabalho dessa natureza, há pesquisas desenvolvidad exclusivamente a partir de fontes bibliográficas.

A partir disso, a presente pesquisa bibliográfica busca refletir acerca da educação inclusiva, no sentido de compreender o que as leis e os pesquisadores definem como sendo a educação inclusiva. Os resultados desta pesquisa foram apresentados nas seções seguintes.

\section{RESULTADOS E DISCUSSÃO}

\section{Aspectos Históricos e Conceituais da}

\section{Educação Inclusiva}

Segundo Schlüzen, Renaldi e Santos (2011) no percurso histórico da Educação Especial pode ser observada quatro fases. A primeira fase é da exclusão, situada antes do século $\mathrm{XX}$, as pessoas na condição de deficiente eram tidas como indignos e impossibilitados de ter acesso ao processo de escolarização, ficavam confinados no lar ou em instituições.

A segunda é a fase da segregação, onde a educação era realizada em institutos à parte, no viés clínico. Observou-se que o pedagógico muitas vezes era esquecido, gerando uma subdivisão na educação: educação normal e educação especial. Apesar das fragilidades e das críticas existentes na atualidade para a educação especial, não se pode negar que para a época (no século XX, na década de 1950) e o seu contexto histórico, essa modalidade de educação considerou as pessoas com deficiência.

O sistema educacional brasileiro cria dois subsistemas (Educação comum e Educação especial), aparentemente com os mesmos objetivos, ou seja, "formar o cidadão para a vida em sociedade e no trabalho". Para esse momento, pode-se dizer que as escolas especiais se constituíram como instituições revolucionárias, pois ofereciam ensino para quem sequer o tinha como direito (SCHLÜZEN; RENALDI; SANTOS, 2011, p.150).

A terceira fase é da integração, ocorrida cerca de 1970 quando aconteceram mudanças e tentativas de inserir as crianças com deficiências nas "escolas regulares". Na prática essa fase se caracterizou pela adaptação do educando à escola:

As avaliações realizadas revelam que a integração dos alunos com necessidades educativas especiais está isenta de problemas e que é imprescindível propor mudanças serão profundas para conseguir escolas aberta a todos. (COOL; MARCHESI; PALÁCIOS, 2004, p. 37).

Já a quarta fase é a da inclusão:
Pressupõem a valorização das diferenças individuais, como possibilidade de crescimento para todas as pessoas, o direito de pertencer e de não ficar de fora e a igual valor para as minorias" (SCHLÜZEN; RENALDI; SANTOS, 2011, p.151).

Segundo Lopes e Fabris (2016, p. 28), esse movimento propõe um olhar diferenciado para as pessoas na condição de deficiencia. Assim, buscase provocar nas pessoas uma atitude contemporânea de sem que se faça isso por 
obrigação. Ou seja,

Que nos possibilite problematizar a inclusão não somente mobilizados pela obediência (pura e simples) à lei, nem pela militância disciplinar (que tem na ordem seu princípio regulador) nem pelo caráter salvacionista (fortemente produzido pelo humanismo e pelas raízes judaico-cristão que carregam) e nem pela necessidade de mudanças emergentes das condições do País frente às exigências do presente. Queremos pensa-la pela vontade de articular a experiências de viver o coletivo e de ter nossas condutas dirigidas de forma mais coerente com a noção de direito, nesse caso, à educação para todos (LOPES; FABRIS, 2016, p. 15).

A exigência é que a escola seja eficiente naquilo que é a sua principal finalidade: ter todas as crianças aprendendo. Não basta, apenas, que as crianças e jovens tenham acesso à escola, é preciso que lá permaneçam e que isso represente desenvolvimento efetivo de conhecimentos, habilidades e competências fundamentais para uma melhor inserção no mundo social, educacional e do trabalho.

No momento atual, no âmbito da educação brasileira fala muito em inclusão, fala-se em estratégias para corrigir as injustiças; algumas estão sendo colocadas em exercício como: criação de ciclos, não reprovação, as correções de fluxo, salas de recursos para atender aos alunos com necessidades especiais entre outras. Contudo, a escola pública brasileira já foi e tem sido praticante excludente e segregadora como destaca (NASCIMENTO; GELATTI, 2015, p.07).

Com vistas nos avanços e na busca de potencializar a inclusão é necessário refletir sobre a importância da educação na vida dos educandos em condição de inclusão. É questionado se o significado da inclusão é, apenas, para preparar o educando com o objetivo de que ele "ganhe a vida", focando no aspecto cognitivo, preparar para o trabalho; sem se importar com o ser completo em seus aspectos cognitivos, sociais, culturais, estético, ético, humano, afetivo, familiar, religioso, etc. Caso a escola focalize, somente, no desenvolvimento cognitivo é possível sugerir que estará deixando em segundo plano a sua função social de formar para vida cidadã

\section{Contexto Escolar e Práticas Pedagógicas Inclusivas}

O papel da escola gravita em torno de processos inclusivos e de cidadania, assim deverá favorecer a cada educando, de forma livre e autônoma, o reconhecimento e o respeito dos direitos dos demais. Neste âmbito, a prática da inclusão social baseia-se em princípios diferentes do convencional: consideração das diferenças individuais, valorização de cada pessoa, convivência dentro da diversidade humana e aprendizagem por meio da cooperação como relata Nascimento e Gelatti (2015, p.02):

\begin{abstract}
Porém, ao se pensar em inclusão, como capacitar os alunos a competirem no mercado de trabalho por bons empregos e bons salários, os alunos não estão sendo incluídos, ao aprovarem apenas por uma correção de ciclo, ou por terem frequentado os $75 \%$ das aulas, esses não estão preparados para competirem num ambiente que não seja paternalista.
\end{abstract}

A prática pedagógica deve orientar e organizar as atividades para assegurar o que está previsto no art. 5 do Estatuto da Criança e do Adolescente, ao defender que:

Nenhuma criança ou adolescente será objeto 
de qualquer forma de negligência, discriminação, exploração, violência, crueldade e opressão, punido na forma da lei qualquer atentado, por ação ou omissão, aos direitos fundamentais" (BRASIL, 2008, p.32).

A Constituição Federal prevê o pleno desenvolvimento dos cidadãos, sem preconceito de origem, raça, sexo, cor, idade, bem como quaisquer outras formas de discriminação. Garante o direito à escola para todos e coloca como princípio o acesso aos níveis mais elevados do ensino, da pesquisa e da criação artística, segundo a capacidade de cada um.

A Lei de Diretrizes e Bases da Educação Nacional - LDBEN/96, por sua vez, ao considerar a Educação Especial uma modalidade de ensino, "caminha com vistas na garantia da educação para os estudantes com necessidades educativas especiais" (NASCIMENTO; GELATTI, 2015).

Contudo, as práticas educativas precisam de fato ser realizadas a partir do que são preconizados pelos documentos normativos e parâmetros legais e pedagógicos. Em relação a isso pode se considerar que:

No plano das ideias, dos discursos e principalmente no papel, a inclusão dos alunos com deficiência no sistema de ensino é uma política impecável, porém, esse modelo de educação inclusiva bem como de currículo, muitas vezes não condiz com a realidade escolar, muito menos com o trabalho do professor, visto que quem o elabora não é aquele que o executa (NASCIMENTO, GELATTI. 201, p.4).

Nesse segmento a prática educativa do (a) pedagogo (a) para uma escola com salas de aula e relações interpessoais inclusivas precisa ser orientada para atender aos interesses e ampliar as capacidades e inserção dos educandos. Para isso, é necessário colocar o educando como centro da aprendizagem, de forma que respeite as suas demandas, para que todos independentes da deficiência possam aprender e se desenvolver.

O educando é, portanto nesse contexto, o foco no processo de aprendizagem e não pode estar em situação de desvantagem social em relação aos seus pares. Dessa forma, importa pensar uma prática inclusiva que possa, a partir de Moran (2005, p. 98):

[...] focar mais a relação afetiva, gostar dos alunos como eles são, chamá-los para participar, aproveitar todo o potencial para motivá-los, valorizá-los, incentivá-los, surpreende-los. Pela interação afetiva creio que conseguiremos encontrar um atalho de aproximação que superará o abismo que separa nosso universo perceptivo, racional e linguístico.

O trabalho do professor passa a ser objeto de uma verdadeira busca pela pratica que parta da realidade encontrada na sala de aula, porém, isso só acontecerá quando começarmos a dar maior importância "ao domínio teórico e prático ligado aos processos de ensino e aprendizagem", "Para atender as crianças reais que estão no cotidiano da escola" como destaca Nascimento; Gelatti (2015, p. 27). Para isso, é necessário deixar de lado os métodos tradicionais, visões estereotipadas e arrigadas que favorecem a segregação e exclusão.

É no contexto educacional que a criança tem possibilidade de ampliar suas experiências e vivências, que ela amplia os valores, as suas relações sociais e sua constituição como um ser humano, mesmo tendo uma constituição biológica/orgânica diferente das demais. Essas ideias têm como base os pressupostos de Vygotsky que contribuem para problematizar a 
educação inclusiva.

Segundo Nuremberg (2008, p.308) as contribuições de Vygotsky para o desenvolvimento de pessoas com deficiência têm um enfoque qualitativo. Vygotsky criticava veementemente o enfoque quantitativo e dos testes de QI, que na sua leitura serviam muito mais para "rotular" os educandos do que para traçar caminhos indiretos para o desenvolvimento do ensino e aprendizagem dos educandos. Como relata Nuremberg (2008, p. 308):

Compreender o desenvolvimento psicológico em crianças com deficiência, assim como compreender alguns problemas pertinentes à neuropsicologia e à psicopatologia, era fundamental ao projeto intelectual de Vygotsky: propor uma teoria geral do desenvolvimento humano. Sua análise da linguagem no desenvolvimento de surdos e cegos, do processo de formação de conceitos em esquizofrênicos e da reabilitação de afásicos vinha a reboque de uma intenção mais ampla: compreender os aspectos da gênese social do funcionamento psicológico superior.

Portanto, Vygotsky enfatizava que por mais que um dos aparatos biológicos do indivíduo esteja comprometido - um dos cinco sentidos e até mesmo o intelectual é possível desenvolver os processos psicológicos superiores. Esse desenvolvimento se daria mediante os caminhos indiretos que seria uma forma compensatória para o desenvolvimento do educando. Mas, isso tem relação com o histórico, o cultural e do como as pessoas pensam e agem em relação a deficiência.

Segundo Vigotski (1983/2011, p.21) “é possível dizer que todas as funções superiores não se formaram apenas na biologia, esse mecanismo, pode ser encontrada na base das funções psíquicas superiores, e sua matriz é social". A aprendizagem e o desenvolvimento da pessoa na condição de deficiência podem ocorrer pelos caminhos indiretos, a partir do plano de desenvolvimento social e o cultural.

A estrutura das formas complexas de comportamento da criança consiste numa estrutura de caminhos indiretos, pois auxilia quando a operação psicológica da criança se revela impossível pelo caminho direto. Porém, uma vez que esses caminhos indiretos são adquiridos pela humanidade no desenvolvimento cultural, histórico, e uma vez que o meio social, desde o início, oferece à criança uma série de caminhos indiretos, então, muito frequentemente, não percebemos que o desenvolvimento acontece por esse caminho indireto (VIGOTSKI, 1983/2011, p. 22).

Porém, esse desenvolvimento psicológico superior terá maiores e até melhores oportunidades de alargar se a escola valorizar o papel social e cultural no processo de aprendizagem e desenvolvimento dos educandos. A escola deve potencializar os caminhos indiretos, levando em consideração não, apenas, a deficiência do educando, mas refletindo sobre as possibilidades existentes e vendo o como sujeito, além da deficiência.

É nesse sentido, que os laudos devem ser usados; não, apenas, para rotular o educando; mas sim para buscar caminhos para o desenvolvimento. Quanto as questões de aprendizagem e desenvolvimento, Figueiredo (2010, p.19) destaca que:

Uma proposta enfim, que atenda as 
diferenças deve [...] levar em conta as características dos alunos respeitando o seu estilo de aprendizagem, ritmo, nível de desenvolvimento intelectual, características do funcionamento cognitivo, além de seu desenvolvimento afetivo-social.

Uma escola para todos implica mudanças nas concepções pedagógicas que "[...] resultem em ações que privilegiem atenção à diferença $\mathrm{e} a$ diversidade". Quando se planeja o processo ensino e aprendizagem é ponto básico a organização da proposta curricular e das práticas desenvolvidas no interior dessa escola, sendo necessário o "[...] reconhecimento das diferentes situações sociais, cognitivas e culturais existentes na sala de aula" (FIGUEIREDO, 2010, p.11).

Percorrendo o histórico da Educação Especial a até chegar na educação inclusiva e considerando a perspectiva histórico e cultural do desenvolvimento humano, considera-se que a Educação Inclusiva é uma necessidade primordial do nosso tempo.

Buscamos na Modernidade ferramentas que possibilitam conhecer e problematizar as tramas discursivas que inventaram a inclusão como uma necessidade primordial do nosso tempo. Discutimos a noção atual e emergente da inclusão buscando entendê-la como um processo datado e advindo dos muito movimentos sociais, econômicos e culturais produzidos na história da humanidade (LOPES; FABRIS; 2016, p 8).

Nessa perspectiva as autoras submetem o conceito de inclusão social à uma crítica radical, fazendo uma discussão sobre os conceitos que antecederam a emergência da inclusão. Apontar o processo de exclusão e de inclusão, está cada vez mais difícil na atualidade, pois "as fronteiras que separam incluídos e excluídos nem sempre são tão visíveis" (LOPES; FABRIS, 2016, p. 8).
Elas usam outras palavras para marcar a condição de discriminação vividas por grupos ou sujeitos silenciados e ignorados pelo Estado e pela sociedade.

A discriminação negativa deve ser entendida e encaminhada diferentemente das discriminações positivas. As discriminações positivas podem ser compreendidas como aquelas que "consistem em fazer mais por aqueles que têm menos" e que possuem como princípio "desdobrar esforços suplementares em favor das populações carentes de recursos afim de integra-los ao regime comum e ajuda-los a reencontrar este regime (LOPES; FABRIS, 2016).

\section{CONSIDERAÇÕES FINAIS}

O presente artigo foi delineado a partir do estudo bibliográfico que possibilitou fazer um breve histórico da Educação Especial no Brasil para refletir acerca do histórico da Educação Inclusiva no Brasil, que está pautada nos Direitos Humanos, na Lei de Diretrizes e Bases da Educação (LDBEN), Estatuto da Criança e do Adolescente (ECA) dentre outros documentos normativos da educação brasileira. A partir deste aporte teórico apresentado acerca da educação inclusiva, considera-se que discriminar positivamente na escola é ação fundamental para que seja possível atender as especificidades da aprendizagem de cada sujeito, ou para incluir a todos. E que é uma das responsabilidades das escolas assegurar um currículo inclusivo, utilizar métodos e recursos que atendam às necessidades de todos os educandos.

Em contrapartida a discriminação negativa é aquela que gera preconceito, marcando ou 
estigmatizando o sujeito. Na acepção de Castel (2008) ser discriminado negativamente é algo que impõe ao sujeito uma condição menor, nesse sentido, embora exista avanços na Educação Especial no Brasil, ainda há caminhos a percorrer tendo em vista que a discriminação precisa ser positiva, com mudanças amplas nas práticas pedagógicas.

Essas mudanças poderão ser potencializadas na formação inicial. Dito isto, é interessante que nos cursos de licenciaturas sejam desenvolvidas práticas pedagógicas voltadas para ações educativas com crianças/educandos em condição de inclusão. Assim, é necessário fazer uma reflexão sobre os pressupostos teóricos e metodológicos nesse viés com vistas num fazer pedagógico inclusivo.

\section{REFERÊNCIAS BIBLIOGRÁFICAS}

BRASIL. Estatuto da Criança e do Adolescente. Ministério da Saúde. - 3. ed. Brasília: Editora do Ministério da Saúde, 2008.96 p. - (Série E. Legislação de Saúde).

CARVALHO, Rosita Edler. Removendo Barreiras para a Aprendizagem, educação inclusiva. Editora Mediação $10^{\circ}$ edição. Porto Alegre 2011.

CASTEL, R. A discriminação negativa.

Cidadãos ou autóctones? Rio de Janeiro: Vozes, 2008.

COLL, César; MARCHESI, Álvaro; PALACIOS, Jésus. (Org). Desenvolvimento psicológico e educação: transtornos de desenvolvimentos e necessidades educativas especiais. Vol. 3. 2 eds. Tradução de Fátima Murad. Porto Alegre: Artmed, 2010.

GIL, Antônio Carlos. Como elaborar projetos de pesquisa. 4. ed. - São Paulo: Atlas, 2002.

LOPES, Maura Corcini; FABRIS, Eki Henn. Inclusão \& Educação. 1 ed. Belo Horizonte: Autentica Editor, 2016.

MORAN, José M. Desafios da televisão e do vídeo à escola. In: MORAN, José M; ALMEIDA, Maria Elizabete Bianconcini de (orgs.).

Integração das tecnologias na Educação. Brasília: MEC, 2005.

NASCIMENTO, Taise Adriana Rodrigues do. GELATTI, Mônica. Os desafios enfrentados pelo pedagogo na construção de uma escola inclusiva. XVII Seminário Internacional da Educação no Mercosul, 2015.

NUERNBERG, Adriano Henrique. Contribuições de Vygotski para a educação de pessoas com deficiência visual. Psicologia em Estudo, Maringá, v. 13, n. 2, p. 307-316, abr./jun. 2008. Disponível em: http://www.scielo.br/pdf/pe/v13n2/a13v13n2.pdf Acesso em: set. 2017.

SCHLÜZEN, Elisa; RINALDI, Renata; SANTOS, Danielle. Inclusão escolar: marcos legais, atendimento educacional especializado e possibilidade de sucesso escolar para pessoas com deficiência. In: UNIVERSIDADE ESTADUAL PAULISTA, Progad. Caderno de Formação: formação de professores didática geral. São Paulo: Cultura Acadêmica, 2011, p. 148-160, v. 9. Disponível em: www2.assis.unesp.br/.../Inclusão\%20Escolar_marc os\%20legais\%20AEE\%20_sucesso. Acesso em: jan. 2017.

SEVERINO, Antônio Joaquim. Metodologia do Trabalho Científico. São Paulo: Cortez, 2007.

VIGOTSKI, L. S. A defectologia e o estudo do desenvolvimento e da educação da criança anormal. Educ. Pesqui, São Paulo, v. 37, n. 4, p. 863-869, dez. 2011. Disponível em: http://www.scielo.br/scielo.php?script=sci_arttext

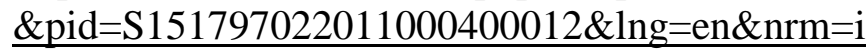
$\underline{\text { so }}$

\section{Como citar este artigo (Formato ABNT):}

SILVA, Édna Leandro; DIAS, Nelson. Refletindo conceitos e legislações acerca da educação inclusiva na perspectiva da prática docente para inclusão. Educação, Psicologia e Interfaces, vol.1, n.2, p. 43-50, 2017. DOI: https://doi.org/10.37444/issn-2594-5343.v1i2.45

Recebido: 02/10/2017.

Aceito: 23/12/2017. 